CORRIGENDUM

\title{
Autophagy suppresses Ras-driven epithelial tumourigenesis by limiting the accumulation of reactive oxygen species
}

J Manent, S Banerjee, R de Matos Simoes, T Zoranovic, C Mitsiades, JM Penninger, KJ Simpson, PO Humbert and HE Richardson

Oncogene (2017) 36, 5658-5660; doi:10.1038/onc.2017.239

Correction to: Oncogene (2017) 36,5576-5592; doi:10.1038/onc. 2017.175; published online 5 June 2017

Since the publication of the above article, the authors have noted an incorrect label 'months' on the x-axis in Figure 3. The correct label should be 'days'. The corrected figure is provided below.

The authors have also noted a missing arrow and a mis-orientated arrow in Figure 9 and an incomplete description in the figure legend. The corrected figure is provided below.

The authors have also noted typographic errors in Supplementary Tables 2 and 3 as well as an error in one of the labels in Supplementary Figure 4. The corrected tables and figure can be found on the Oncogene website.

The final versions of Datasets 1 and 2 have now also been provided as part of the supplementary material.
The amendments made in this corrigendum do not affect the outcome of the research reported. The authors apologise for any inconvenience caused by these errors. These errors have now been rectified. The html and online pdf versions have also been rectified, and now carry the corrected paper.

(c) (i) This work is licensed under a Creative Commons Attribution 4.0 International License. The images or other third party material in this article are included in the article's Creative Commons license, unless indicated otherwise in the credit line; if the material is not included under the Creative Commons license, users will need to obtain permission from the license holder to reproduce the material. To view a copy of this license, visit http://creativecommons.org/licenses/ by/4.0/

(c) The Author(s) 2017 
GABARAP

GABARAP,PAADLOG1P bestcutoff $39 \%$ survivalplot

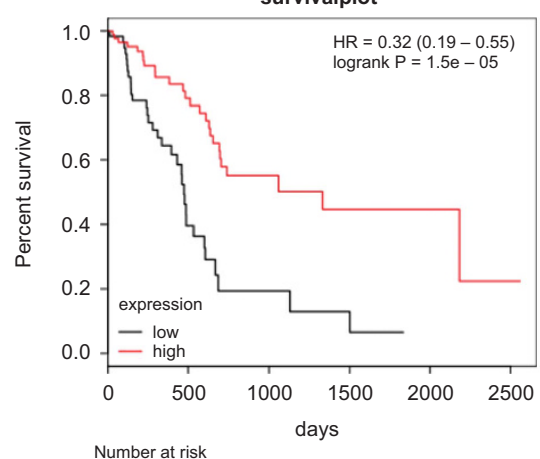

$$
\text { low } \quad 69 \quad 12
$$

C
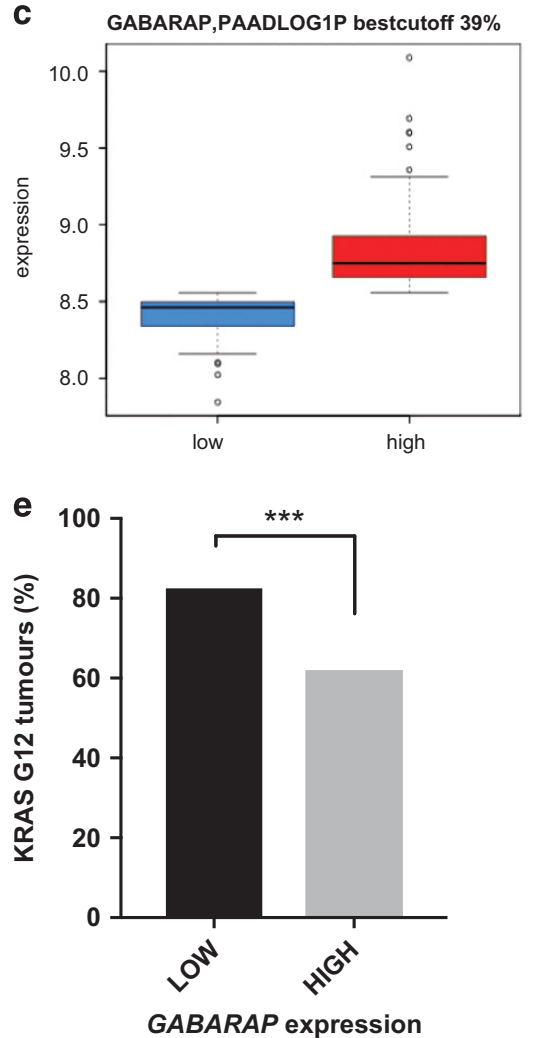

b

\section{VAMP2}
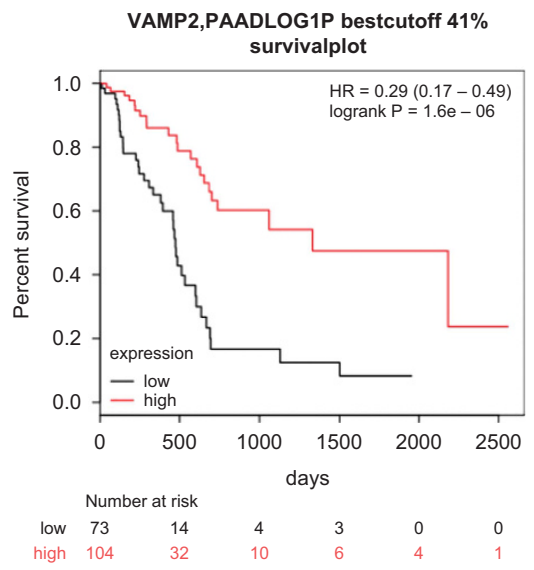

d
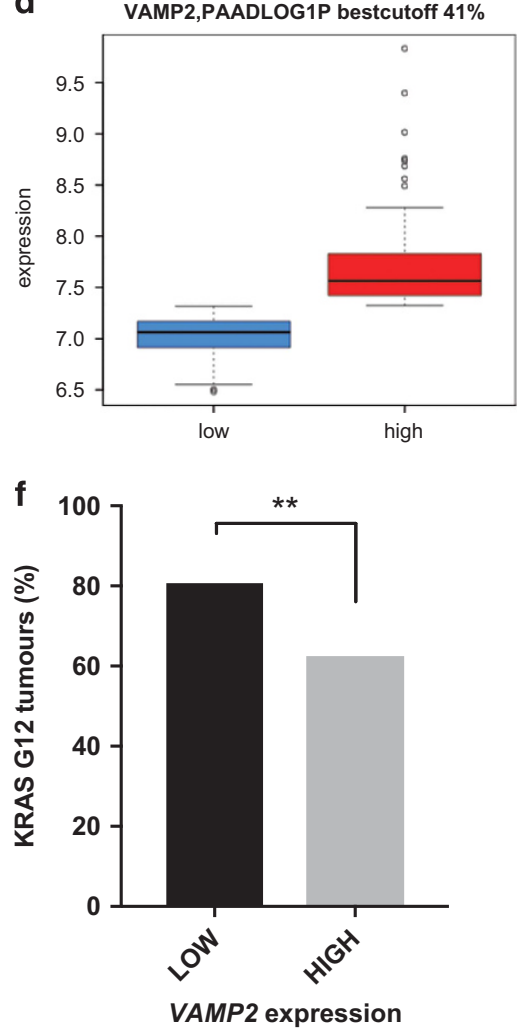

Figure 3. Low expression of GABARAP and VAMP2 is prognostic for worse survival in KRAS-G12-positive PAAD. Survival curves of PAAD patients with low (black) or high (red) expression of GABARAP (a) and VAMP2 (b). Low expression of GABARAP (c) or VAMP2 (d) correlates with worse clinical outcome in patients ( $\mathbf{a}$ and $\mathbf{b}$ ) and with enrichment for G12-activating mutations in KRAS (e and $\mathbf{f}$ ), suggesting that these autophagyrelated genes behave as tumour suppressors in PAAD with KRAS-activating mutations. Statistics: Fisher's exact $t$-test. 


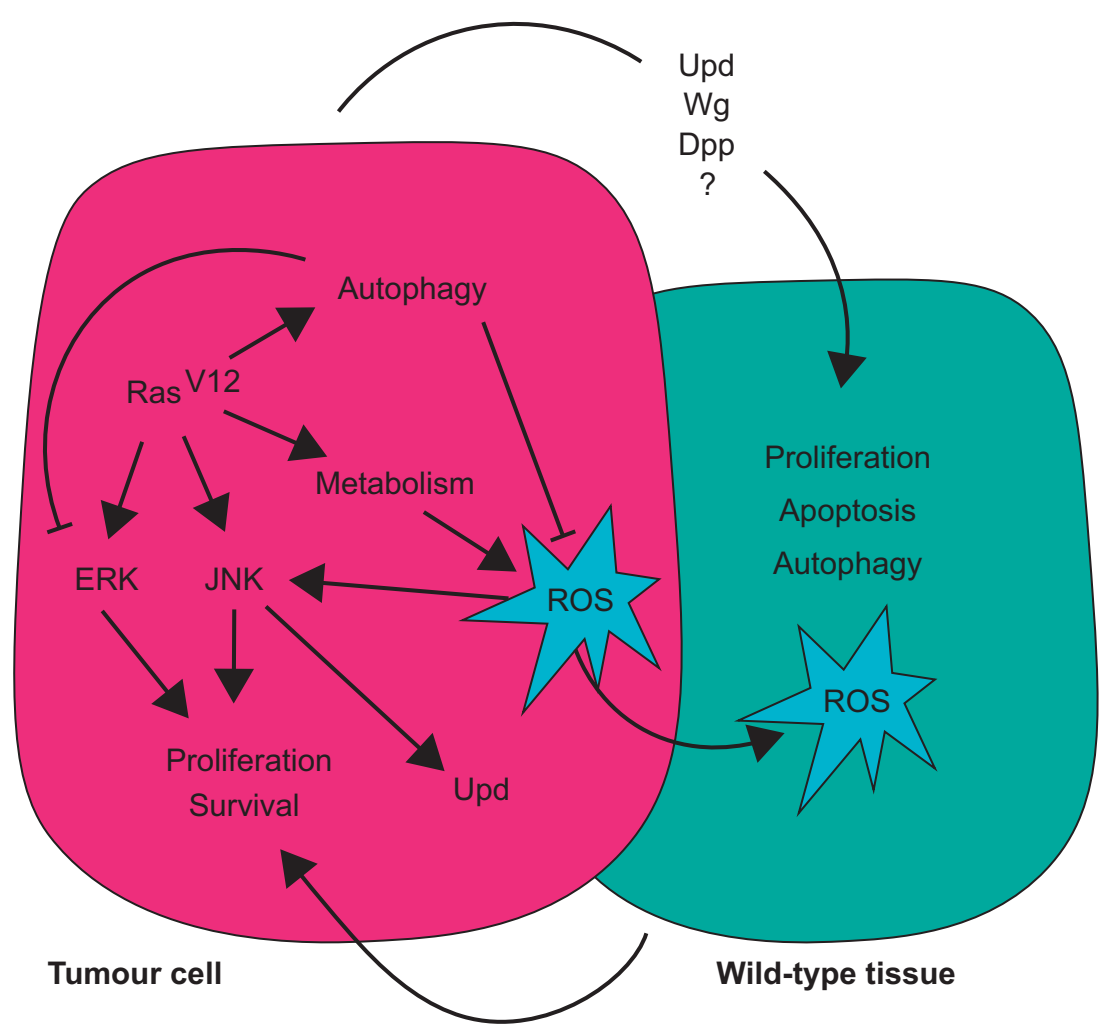

Figure 9. Model of cooperation between Ras and the autophagy pathway. Autophagy induction upon Ras-activation limits the accumulation of reactive oxygen species (ROS) and the activation of the ERK pathway. When autophagy is blocked in Ras ${ }^{V 12}$-expressing cells, ERK is further activated, ROS accumulate and activate the JNK pathway, resulting in cooperative overgrowth of Ras ${ }^{\text {12 }}$ tissues by cell-autonomous and noncell autonomous mechanisms. ROS are detected in neighbouring wild-type tissue, and non-cell autonomous activation of autophagy, proliferation, caspase activation and cell death is observed, which might feed back to promote the proliferation and survival of the Ras ${ }^{1 / 2}$ cells. 